\title{
Numerical Study on Spray Drying Process: Effect of Nonuniform Temperature Field and Interaction between Droplets on Evaporation Rates of Individual Droplets
}

\author{
Sayaka Okada, Shuji Ohsaki,* Hideya Nakamura, and Satoru Watano* \\ Department of Chemical Engineering, Osaka Prefecture University; 1-1 Gakuen-cho, Naka-ku, Sakai 599-8531, \\ Japan. \\ Received October 1, 2020; accepted November 18, 2020
}

\begin{abstract}
Spray drying process is widely used to produce particulate materials in the pharmaceutical industries, such as porous materials for direct compression, solid dispersion for improvement of drug dissolution properties, micro encapsulation to stabilize active compounds, taste masking, preparation of dry powder for inhalation. However, as many factors affect the physical properties of dried particles and the spray drying processes have complex behaviors in which heat and mass transfer occur simultaneously, the detailed mechanisms of dry particle generation have yet to be sufficiently elucidated. In this study, computational fluid dynamics was used to simulate water droplet evaporation in a spray dryer, and the evaporation kinetics of "individual droplets" in the droplet aggregate (group) were analyzed. The numerical simulation revealed that each droplet had different evaporation rates owing to the following two reasons. First, the driving force of evaporation, $\Delta T$, changed every moment as the droplets traveled through different temperature fields in the drying tower. Second, it was calculated the driving force for droplet evaporation differed from the ideal system because the evaporation of other droplets changed the fluid characteristics around the droplets. The obtained results are important findings that lead to the understanding the spray drying process to design and manufacture the pharmaceutical products.
\end{abstract}

Key words spray drying; evaporation process; computational fluid dynamics simulation; discrete phase model; $D^{2}$-law

\section{Introduction}

In the pharmaceutical industries, spray drying is a frequently and widely used process to produce particulate materials. ${ }^{1,2)}$ Spray drying is a continuous production method of dry powders from a liquid-solution/suspension with hot air. Since the dry powders can be obtained by a single process from raw liquid materials, spray drying offers many advantages, such as easy operation, processing of heat-sensitive materials, mass production, and quality control. These advantages of spray drying have garnered much attention to the application to continuous pharmaceutical manufacturing. For instance, the spray drying process is useful in producing solid dispersions that disperse the drug on a carrier to make it amorphous. ${ }^{3-5)}$ The production of solid dispersions is one of the most commonly applied pharmaceutical approaches to increase the bioavailability of water poorly soluble drugs. Moreover, spray-dried powders having a porous structure and well plastic deformability are effective for a direct compression. ${ }^{6}$ The other application includes micro encapsulation to stabilize active compounds, ${ }^{7,8)}$ taste masking, ${ }^{9)}$ and preparation of dry powder for inhalation. ${ }^{10)}$ As mentioned above, much pharmaceutical design formulation using spray drying have been reported. However, as the spray drying processes have complex behaviors in which heat and mass transfer occur simultaneously, the operating conditions affect each other significantly in a complex manner, determining the physical properties of the dry powders. Currently, the optimal equipment design and operating conditions to produce the desired product are primarily conducted by trial and error by skilled engineers. This is because spray drying involves complex fluid behaviors with heat and mass transformation. To understand the mechanism of dry powder generation in a spray dryer, the droplet evaporation process must be clarified.

To understand the drying process of single droplet, experimental investigations by directly observing dry powder generation have been conducted, ${ }^{11)}$ in which the characteristic drying curve (CDC) is the fundamental concept of the droplet drying process. The CDC includes the following three steps: initial, constant rate, and falling rate periods. Based on the observation results and the CDC, many models and theories have been proposed to describe the generation process of dry powder from a single droplet. ${ }^{12-16)}$ Focusing on the behavior of the solid phase during the drying process, the development of the shell formation theor ${ }^{17)}$ and the introduction of a solid diffusion coefficient ${ }^{18)}$ have been reported. Although many drying models/theories for a single droplet have been proposed, they are insufficient for understanding the droplet drying process inside a spray dryer. It is because enormous number of droplets are generated by the spraying and each droplet dry while interacting each under the non-uniform local fluid conditions. To accurately understand the spray drying process, it is necessary to analyze the effects of interaction between droplets in nonuniform temperature fields. However, the experimental approaches are limited because of the complex drying characteristics. Therefore, a numerical approach using computational fluid dynamics (CFD) is effective because it considers multiphase transport inside a spray dryer. To use the CFD, researchers have introduced the Eulerian-Lagrangian approach, which describes multiphase transport phenomena. ${ }^{19)}$ By combining the drying models/theories with the CFD 
simulations, many researchers have analyzed the behaviors of both fluids (velocity, humidity, and temperature) and droplets (particle size distribution and moisture content) inside a spray dryer. $^{20)}$ In addition, the effect of drying condition and the drying tower geometry on the fluid behavior and droplet trajectory have been investigated. ${ }^{21-25)}$ Recently, the CFD studies that considered the collision between droplets (or particles) and deposition on a spray dryer wall have increased, and the importance of the boundary condition between a particle and wall has been discussed. ${ }^{26-30)}$

Previous studies have primarily focused on a single droplet drying or the overall fluid and droplet drying behaviors inside a spray dryer. Normally, in the spray drying process, numerous sprayed droplets form a tear-shaped droplet aggregate (group), which is then dried in a non-uniform temperature field. Here, we defined the aggregate (not coalescence) of droplets as the droplet group. The simple analyses on the single droplet drying and the entire behavior inside the spray dryer are not sufficient to be used for the process design of the spray drying including a scale-up. The drying kinetics of "individual droplets" in the spray drying process is still missing in the literature. It is also necessary to analyze the effect of interaction between each droplet in a nonuniform temperature field on the evaporation rate of the droplet group. Before developing a new drying model and numerical approach, we recognize that it is important to understand the drying behavior of individual droplets in the droplet group. Although some papers have been reported the analysis focusing on only one droplet in the droplet group, ${ }^{31-33)}$ few analyses such as the distribution of the drying rate of individual droplets have been reported. In the present study, a numerical analysis using the CFD was performed to investigate the evaporation behavior of droplet group, including the evaporation kinetics of individual droplets in a spray dryer. As the first step, focusing on the constant rate period in the $\mathrm{CDC}$, the evaporation kinetics of a water droplet group were analyzed by comparing them with the ideal drying theory of a single droplet. The reason why water was used is to investigate the constant rate period. Even if the droplet contains solid components, the drying of free water can be comparable to that of the only water droplet. Unlike our previous study, ${ }^{34)}$ which focused on the relationship between the operating conditions and the evaporation rate of the individual droplet, this study investigates the effects of droplet group and fluid dynamics inside a spray dryer on the evaporation kinetics of individual droplets in detail.

\section{Simulation Method}

Simulation Model To simulate the spray evaporation process of a droplet group, a coupled model combining the CFD and a discrete phase model (DPM) ${ }^{26)}$ was used. The continuous phase was calculated through the Eulerian approach. The Lagrangian approach tracked the droplet motions as a discrete phase. A two-way coupling of the steady continuous and dispersed droplet phases was implemented in this study. In other words, the interphase exchange of heat, mass, and momentum between the fluid and droplet were fully considered. The continuous- and discrete-phase equations were alternately solved until a converged solution was obtained in both phases.

The continuous phase was calculated as incompressible air. The governing equations for a gas-liquid multiphase flow include the continuity equation, Navier-Stokes equation, and energy equation. The continuity equation considering the mass transfer from the discrete phase to the continuous phase is expressed as

$$
\rho \cdot \nabla \boldsymbol{u}=M,
$$

where $M$ is the molar mass added to the continuous phase from the discrete phase owing to the vaporization of liquid droplets. The mass transfer can be computed by examining the change in mass of a droplet as it passes through each control volume:

$$
M=\frac{\mathrm{d} m_{\mathrm{d}}}{\mathrm{d} t} \frac{\dot{m}_{\mathrm{d}, 0}}{m_{\mathrm{d}, 0}},
$$

where $m_{\mathrm{d}, 0}$ and $\dot{m}_{\mathrm{d}, 0}$ are the initial mass of the droplet and the initial mass flow rate of the droplet injection, respectively. The Navier-Stokes equation is given by

$$
\frac{\partial}{\partial t}(\rho \boldsymbol{u})+\nabla \cdot(\rho \boldsymbol{u} \boldsymbol{u})=-\nabla p+\nabla \tau+\rho \boldsymbol{g}+\boldsymbol{F},
$$

where $p$ is the pressure, $\tau$ is the stress tensor, and $\rho \boldsymbol{g}$ is the gravitational body force. $\boldsymbol{F}$ is the momentum transfer from the continuous phase to the discrete phase (fluid drag force) as follows:

$$
\boldsymbol{F}=\sum\left[\frac{18 \mu C_{\mathrm{D}} R e}{\rho_{\mathrm{d}} d^{2} 24}\left(\boldsymbol{u}_{\mathrm{d}}-\boldsymbol{u}\right)\right] \dot{m}_{\mathrm{d}} \Delta t
$$

The energy equation is described by

$$
\begin{aligned}
& \frac{\partial}{\partial t}(\rho E)+\nabla \cdot[\boldsymbol{u}(\rho E+p)] \\
& \quad=\nabla \cdot\left[k_{\mathrm{eff}} \nabla T-\sum_{j} h_{j} \boldsymbol{J}_{j}+\left(\tau_{\mathrm{eff}} \cdot \boldsymbol{u}\right)\right]+Q,
\end{aligned}
$$

where $k_{\text {eff }}$ is the effective conductivity, and $J$ is the diffusion flux of species $j$. The first three terms on the right side of Eq. 5 represent energy transfer owing to conduction, species diffusion, and viscous dissipation, respectively. $Q$ is the heat transfer from the continuous phase to the discrete phase, and it can be obtained using the following equation:

$$
Q=\frac{\dot{m}_{\mathrm{d}, 0}}{m_{\mathrm{d}, 0}}\left[\begin{array}{c}
\left(m_{\mathrm{d}, \text { in }}-m_{\mathrm{d}, \text { out }}\right)\left[-H_{\mathrm{lat}}+H_{\mathrm{pyrol}}\right] \\
-m_{\mathrm{d}, \text { out }} \int_{T_{\mathrm{ref}}}^{T_{\mathrm{d} \text {,out }}} c_{p} \mathrm{~d} T+m_{\mathrm{d}, \text { in }} \int_{T_{\mathrm{ref}}}^{T_{\mathrm{d} \text {,in }}} c_{p} \mathrm{~d} T
\end{array}\right],
$$

where the subscripts "in" and "out" represent the cell entrance and the exit, respectively. $H_{\text {lat }}$ is the latent heat at the reference conditions, and $H_{\text {pyrol }}$ is the pyrolysis heat as volatiles are evolving. The pressure-velocity coupling of the flow field was calculated using the semi-implicit method for pressure-linked equation algorithm (SIMPLE). ${ }^{35)}$ Furthermore, the realizable $k-\varepsilon$ model $^{36}$ ) was used as a turbulence model, which was often used to calculate the spray drying process in the previous studies. ${ }^{20,24,25)}$ By setting the time derivative to zero, the conservation equations above were solved as a steady-state formulation.

The evaporation rate from the droplets to the continuous phase can be calculated by 


$$
\frac{\mathrm{d} m_{\mathrm{d}}}{\mathrm{d} t}=-\pi d^{2} M_{1} k_{\mathrm{c}}\left(C_{\mathrm{sur}}-C_{\mathrm{f}}\right)
$$

where $C_{\text {sur }}$ and $C_{\mathrm{f}}$ denote the molar concentrations of vapor on the droplet surface and in the ambient air, which are respectively calculated by

$$
\begin{gathered}
C_{\text {sur }}=\frac{p_{\text {sat }}\left(T_{\mathrm{d}}\right)}{R T_{\mathrm{d}}} \\
C_{\mathrm{f}}=\frac{p_{\mathrm{op}}}{R T_{\mathrm{f}}}
\end{gathered}
$$

where $p_{\text {sat }}$ and $p_{\text {op }}$ are the saturated vapor pressure and the local absolute pressure, respectively. The coefficient of mass transfer between the droplet and air can be described by the Ranz-Marshall equation ${ }^{37)}$ :

$$
S h=\frac{k_{\mathrm{c}} d}{D_{\mathrm{AB}}}=2.0+0.6 R e_{\mathrm{d}}^{1 / 2} S c^{1 / 3}
$$

The motion of the droplets can be described by Newton's second law:

$$
\frac{\mathrm{d} \boldsymbol{u}_{\mathrm{d}}}{\mathrm{d} t}=\frac{18 \mu_{\mathrm{f}} C_{\mathrm{D}} R e}{24 \rho_{\mathrm{d}} d^{2}}\left(\boldsymbol{u}-\boldsymbol{u}_{\mathrm{d}}\right)+\frac{\boldsymbol{g}\left(\rho_{\mathrm{d}}-\rho_{\mathrm{f}}\right)}{\rho_{\mathrm{d}}}
$$

The terms on the right side of Eq. 11 represent the drag force and the force owing to gravity. The drag force depends on the droplet diameter, $d$, and changes through the droplet evaporation. The droplet temperature is updated according to the heat balance based on the sensible heat changes in the droplet, latent heat transfer through evaporation of droplets, and convective heat transfer between the droplet and continuous phase:

$$
m_{\mathrm{d}} c_{p} \frac{\mathrm{d} T_{\mathrm{d}}}{\mathrm{d} t}=-\frac{\mathrm{d} m_{\mathrm{d}}}{\mathrm{d} t} h_{\mathrm{fg}}+h \pi d^{2}\left(T_{\mathrm{f}}-T_{\mathrm{d}}\right)
$$

where $h_{\mathrm{fg}}$ is the specific heat of evaporation, and $h$ is the coefficient of heat transfer between the droplet and air, which can be obtained by the Ranz-Marshall equation ${ }^{37)}$.

$$
N u=\frac{h d}{k_{\mathrm{f}}}=2.0+0.6 \operatorname{Re}_{\mathrm{d}}^{1 / 2} \operatorname{Pr}^{1 / 3}
$$

The convective heat transfer also depends on the droplet diameter, $d$, and changes through the droplet evaporation. Based on the drying condition used in this study, the droplet concentration inside the drying tower can be assumed as sufficiently dilute (less than 10\%) and that the droplets were evaporated before adhering to the wall surface. Based on this assumption, droplet-droplet and droplet-wall collisions were neglected. In addition, even when preparing formulation in the pharmaceutical field by the spray drying process, the droplet-droplet and droplet-wall collisions would be caused by undried droplets during the falling drying rate period. Therefore, it was safe to ignore the collision in the analysis during the constant drying rate period.

Model Geometry The full three-dimensional (3D) geometry of the cylinder-on-cone spray dryer used in the experiments was created using Design Modeler (Ver. 17.2, ANSYS Inc., U.S.A.). The calculation domain was same as that in the (a)

(b)

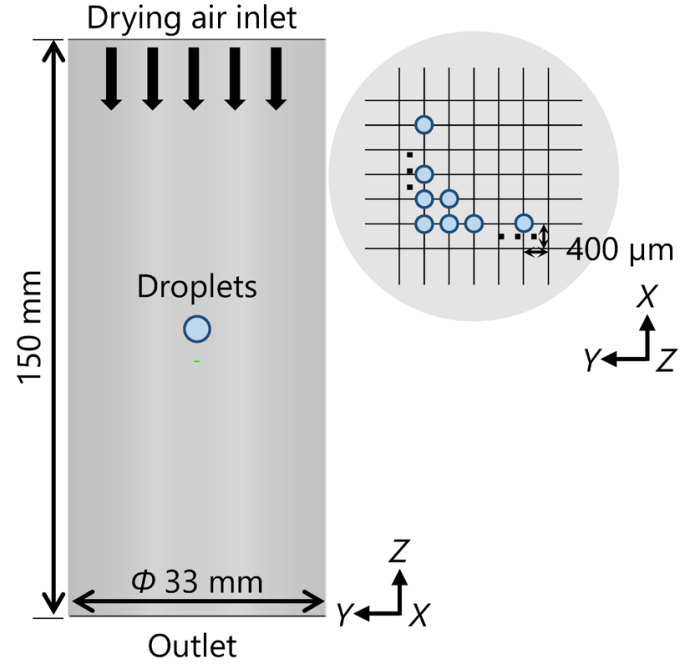

Fig. 1. (a) Schematics of Simple Cylinder; (b) Arrangement of 1-300 Droplets in a Grid at Center of Simple Cylinder

(Color figure can be accessed in the online version.)

previous paper. ${ }^{34)}$ The geometry of the two-fluid nozzle was simplified to improve the convergence. The spray air was considered to flow from the plane in our simulations. The nozzle diameter was set to $6.2 \mathrm{~mm}$. The numerical mesh of the spray dryer was developed by ANSYS Meshing (Ver. 17.2, ANSYS Inc.). A series of numerical meshes, which involved different types and numbers of elements, was tested. The detailed results are summarized in the Supplementary Material. Finally, a tetrahedron and layer meshes were used for the accurate calculation of the velocity profile near the wall. The tetrahedron mesh used in this study comprised 1672024 elements (the grid size was $5 \mathrm{~mm})$.

To analyze the evaporation kinetics of a single droplet or droplets in the droplet group in the air stream, CFD-DPM calculations were performed using a simple geometry. The computational domain was a cylinder (Fig. 1 (a)) with a total length of $150 \mathrm{~mm}$ and an inner diameter of $33 \mathrm{~mm}$. The numerical mesh comprised tetrahedron elements measuring $0.5 \mathrm{~mm}$.

Simulation Conditions The numerical solution of the model equations and computational simulations were obtained and performed, respectively, using the 3D pressure-based solver incorporated in the CFD package FLUENT (Ver. 17.2, ANSYS Inc.). The following strategy was used for the numerical simulations. First, the flow field of drying air and spray air were calculated without the discrete phase until a converged solution was obtained. Subsequently, the droplet group was injected into the computational domain, and two-way coupled calculations were performed.

The physical properties of water were used for the droplet parameters. The spray injection from the two-fluid nozzle was represented by 200 droplet streams per single time step. The initial droplet velocity was set to $14 \mathrm{~m} / \mathrm{s}$. The droplets and spray air were assigned a swirl component that was 0.4 times the axial velocity. This swirl component was determined to reproduce the experimental fluid temperature distribution and droplet group shape inside the drying tower. As the boundary condition, the outlet pressure at the lower end of the drying tower was set to $1 \mathrm{~atm}$. The coefficient of heat transfer from 
the walls to the surrounding air was estimated from the following Colburn's equation ${ }^{38)}$ :

$$
\frac{h_{\mathrm{col}} D}{k_{\mathrm{f}}}=0.023\left(\frac{D G}{\mu_{\mathrm{f}}}\right)^{0.8}\left(\frac{c_{p} \mu}{k}\right)_{\mathrm{f}}^{1 / 3}
$$

The wall thickness of the drying tower was assumed to be $1.5 \mathrm{~mm}$, and the thermal conductivity was set to $16.7 \mathrm{~W} / \mathrm{m} \cdot \mathrm{K}$. The film coefficient of heat transfer $h_{\text {col }}$ was $8.978 \mathrm{~W} / \mathrm{m}^{2} \cdot \mathrm{K}$, calculated by Eq. 14 using the air property based on the average film temperature of $345 \mathrm{~K}$. Nonslip wall boundaries were used on either side of the numerical domain. The DPM timestep was set as $1 \times 10^{-5} \mathrm{~s}$ based on the element length and local droplet velocity.

The calculation of the spray drying process was performed for $0.2 \mathrm{~s}$. The initial $0.1 \mathrm{~s}$ was considered as the stabilization time, and the next $0.1 \mathrm{~s}$ was used to analyze the drying process. The number of droplets in the spray dryer gradually increased from the start of calculation and reached to constant number within the initial $0.1 \mathrm{~s}$. Since this study focused on the water droplet group, the evaporation process (not drying process) was evaluated. The evaporation time, driving force for evaporation, and evaporation rate were calculated using 10000 random droplets selected from the droplet group introduced into the drying tower after the initial $0.1 \mathrm{~s}$. The evaporation time was calculated from the residence time until the droplet evaporated completely. The driving force for the evaporation was evaluated with a temperature difference $(\Delta T)$ between the droplet and the surrounding air, as written in Eq. 8; $\Delta T$ was obtained as temperature differences between the droplet and the node point closest to the coordinates of the droplet.

In the calculation using the simple cylinder, 1-300 droplets were arranged in a grid at the center of the tower with a distance from the droplet centers of 19.6-400 $\mu \mathrm{m}$ (Fig. 1 (b)). The drying air flow rate was set the same as the boundary condition of the spray drying calculation. The initial droplet velocity was $0 \mathrm{~m} / \mathrm{s}$, and it was allowed to fall free. Table 1 summarizes the simulation conditions of the spray dryer and the simple cylinder. The physical properties of water were used for the droplet parameters. A droplet diameter of $19.6 \mu \mathrm{m}$ was determined from the median size measured using a laser

Table 1. CFD-DPM Calculation Conditions with a Spray Drying Tower and Simple Cylinder

\begin{tabular}{|c|c|c|}
\hline \multicolumn{3}{|c|}{ Simulation (Spray drying) } \\
\hline Inlet drying air velocity & 2.1 & {$[\mathrm{~m} / \mathrm{s}]$} \\
\hline Inlet spray air mass flow rate & $4.34 \times 10^{-4}$ & {$[\mathrm{~kg} / \mathrm{s}]$} \\
\hline Outlet pressure & 101325 & {$[\mathrm{~Pa}]$} \\
\hline Inlet drying air temperature & 423 & {$[\mathrm{~K}]$} \\
\hline Particle time step & $1.0 \times 10^{-5}$ & {$[\mathrm{~s}]$} \\
\hline Liquid feed rate & $3.33 \times 10^{-5}$ & {$[\mathrm{~kg} / \mathrm{s}]$} \\
\hline Droplet size & 19.6 & {$[\mu \mathrm{m}]$} \\
\hline \multicolumn{3}{|c|}{ Simulation (Cylinder) } \\
\hline Inlet drying air velocity & 2.83 & {$[\mathrm{~m} / \mathrm{s}]$} \\
\hline Outlet pressure & 101325 & {$[\mathrm{~Pa}]$} \\
\hline Inlet drying air temperature & 423 & {$[\mathrm{~K}]$} \\
\hline Particle time step & $1.0 \times 10^{-5}$ & {$[\mathrm{~s}]$} \\
\hline Diffusion coefficient & $2.88 \times 10^{-5}$ & {$\left[\mathrm{~m}^{2} / \mathrm{s}\right]$} \\
\hline Droplet size & 19.6 & {$[\mu \mathrm{m}]$} \\
\hline
\end{tabular}

diffraction device.

The evaporation rate of the droplets was calculated based on the $D^{2}$-law, ${ }^{39)}$ which was first developed by assuming quiescent air in the surrounding of the droplet. The $D^{2}$-law can predict a linear decrease in the squared droplet diameter with time, which occurs at a constant temperature (wet bulb temperature) and is described by

$$
-\frac{\mathrm{d} d^{2}}{\mathrm{~d} t}=K=\text { const. }
$$

where $K$ is the evaporation rate constant. A larger $K$ indicates a larger evaporation rate. In this study, $K$ was calculated by tracking each of the 10000 droplets' diameter.

\section{Results and Discussion}

Evaporation Time in Spray Dryer Calculated by CFDDPM Model The evaporation process of the droplet group in the drying tower was calculated using the CFD-DPM model. We confirmed that the numerical simulations represented the trends and values of the experimental outlet temperatures and radius temperature distributions with a high degree of accuracy, as reported in the previous study. ${ }^{34)}$ Figure 2 (a) shows the frequency distribution of the droplet evaporation time obtained from each droplet. The average droplet evaporation time was $0.067 \pm 0.013 \mathrm{~s}$. The time for the droplet to dry completely under a steady condition, in which the surrounding air temperature does not change, can be described by

$$
t=\frac{\rho_{\mathrm{p}} h_{\mathrm{fg}}}{4 k_{\mathrm{f}} \Delta T} \times \frac{1}{2} d^{2}
$$
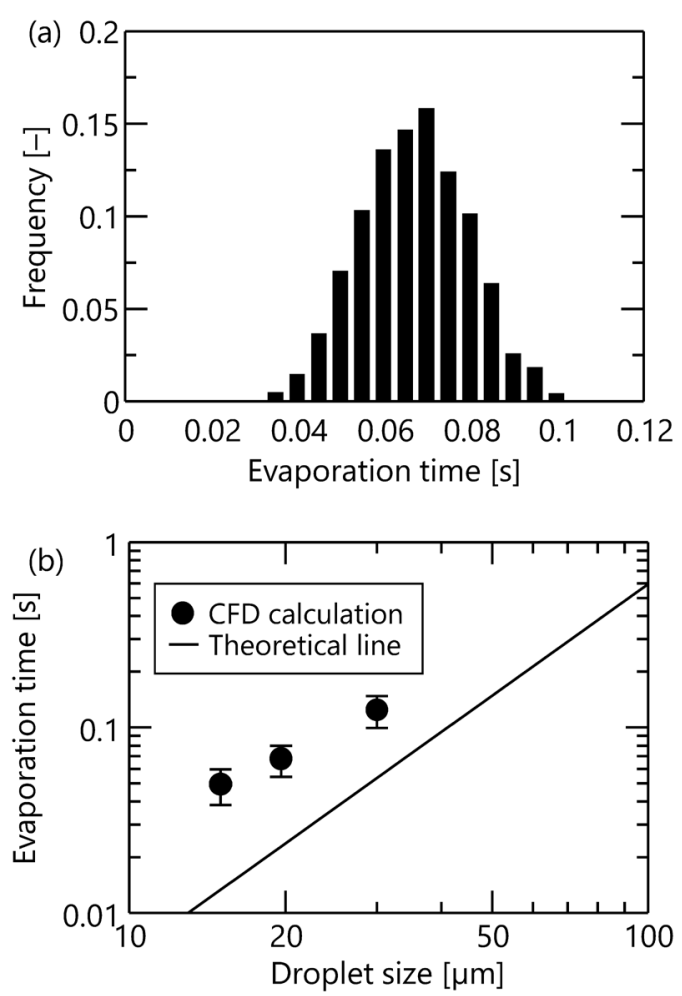

Fig. 2. (a) Frequency Distributions of Droplet Evaporation Time; (b) Comparison between Theoretical and Calculated Evaporation Times of Droplet under Different Droplet Diameters 
where $k_{\mathrm{f}}$ is the thermal conductivity of the continuous phase; $\Delta T$ is the temperature difference between the droplet and the surrounding air. Figure 2 (b) shows the theoretical (line) and the calculated (markers) droplet evaporation time. The CFD simulation was performed with droplet sizes of not only $19.6 \mu \mathrm{m}$ but also 15 and $30 \mu \mathrm{m}$ to compare the theoretical evaporation time of droplet. Droplet diameters of 15 and $30 \mu \mathrm{m}$ were determined based on the computational stability and complete evaporating before reaching the tower wall. The theoretical droplet evaporation time was calculated based on Eq. 16 with $\Delta T=106 \mathrm{~K}$ under the assumption that the droplet evaporation progressed with the ambient air temperature of $423 \mathrm{~K}$ and the droplet maintained the wet-bulb temperature of $317 \mathrm{~K}$. The result shows that there was a difference between the theoretical evaporation time calculated using $\Delta T$ determined from the experimental conditions and the calculated one. The calculated droplet evaporation time was 2-3.5 times longer than the theoretical one, which can be attributed to two reasons. The first is the presence of air temperature distribution, and the second is the effect of existing droplets in the drying tower. In the drying tower, owing to its complicated fluid behavior of the droplets and the effect of other droplets in the group, the droplet evaporation kinetics were differed considerably from the ideal condition. Therefore, the obtained results suggested the necessity to analyze the individual droplet evaporation behavior in terms of temperature and droplet diameter change for verifying these two hypotheses.

Evaluation of Evaporation Rate Constant in Spray Dryer The evaporation rate constant, $K$ of each droplet was calculated from the time change in droplet diameter squared based on Eq. 16. Figure 3 indicates the frequency distribution of $K$, and the average of $K$ was $5.639 \times 10^{-9} \mathrm{~m}^{2} / \mathrm{s}$. Despite spraying with monodisperse droplets, the droplets were evaporated at individual evaporation rates. This result will be the first quantitative determination of the evaporation rate constant of individual droplets in the spray drying process. The detailed discussion will be proceed based on these obtained findings. To investigate the droplet evaporation behavior in detail, two arbitrary droplets (droplets $\mathbf{A}$ and $\mathbf{B}$ ) with different $K$ were selected from the sprayed droplet group. Figure 4 (a) shows the temporal change in the droplet diameter squared and the $\Delta T$ of the two selected droplets. In the case of droplet A (yellow plots), the $D^{2}$-plots indicated a curve, and $\Delta T$ varied significantly during the evaporation process. Meanwhile, in

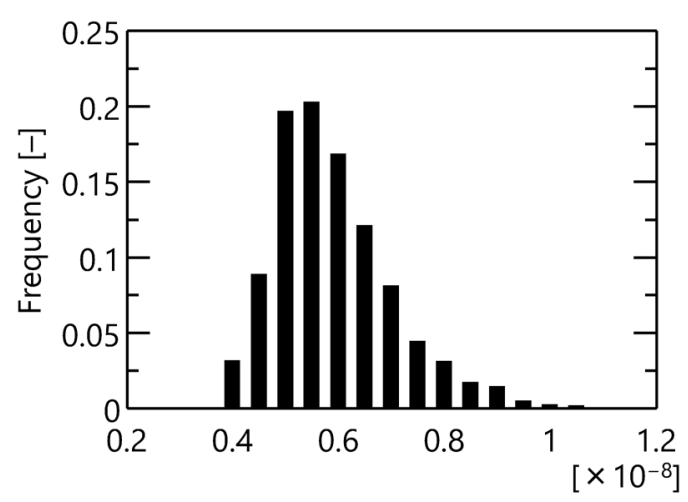

Evaporation rate constant, $K\left[\mathrm{~m}^{2} / \mathrm{s}\right]$

Fig. 3. Frequency Distributions of Evaporation Rate Constant $K$ of Each Droplet the case of droplet $\mathbf{B}$ (red plots), the $D^{2}$-plots were approximately a straight line, and $\Delta T$ was constant. This result shows that the evaporation rate constant $K$ depends significantly on the temperature difference $\Delta T$ between the droplet and ambient air. Figure 4 (b) shows the snapshot of the droplet trajectories depicted on the air temperature profiles. As shown, each droplet followed a different track. Droplet A passed through the high-temperature region immediately after the spraying, while droplet $\mathbf{B}$ passed through the much lower-temperature region. Such a difference in the droplet tracks resulted in different $\Delta T$.

The relationship between $\Delta T$ variation and the distribution of $K$ in the droplet group was investigated. The values of the square of the coefficient of correlation, $R^{2}$ were determined by the linear least-squares regression of the $D^{2}$-plots. When $\Delta T$ barely changes, the $D^{2}$-plots becomes a straight line $\left(R^{2}=1\right)$. Meanwhile, when the variation of $\Delta T$ is large, the $D^{2}$-plots becomes a curve and the $R^{2}$ value becomes smaller than 1 . Figure 5 shows the relationship between the droplet evaporation time and $K$, in which the plot colors reflect the $R^{2}$ value. The

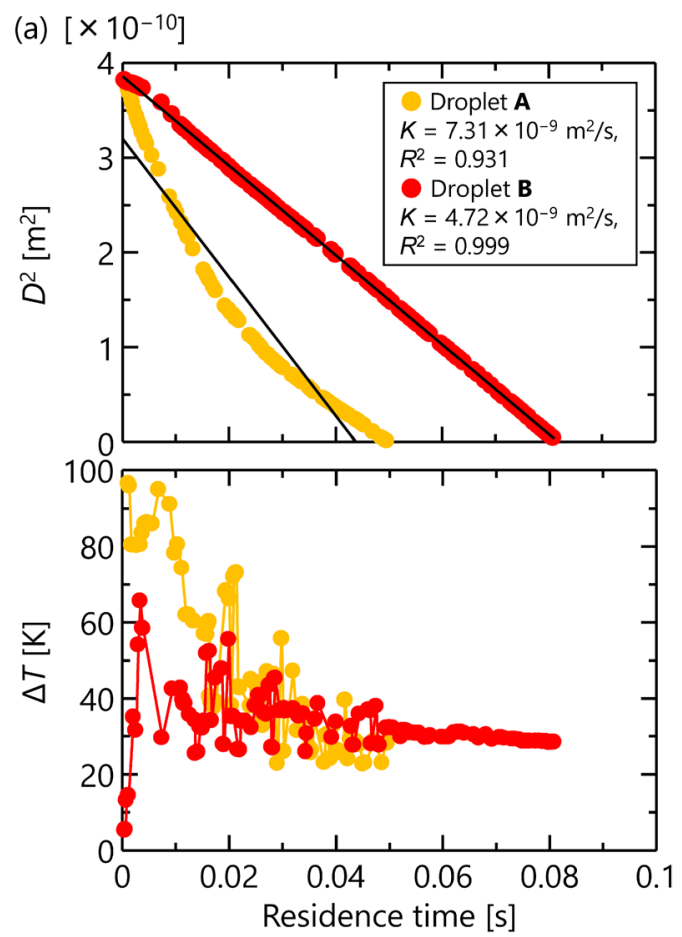

(b)

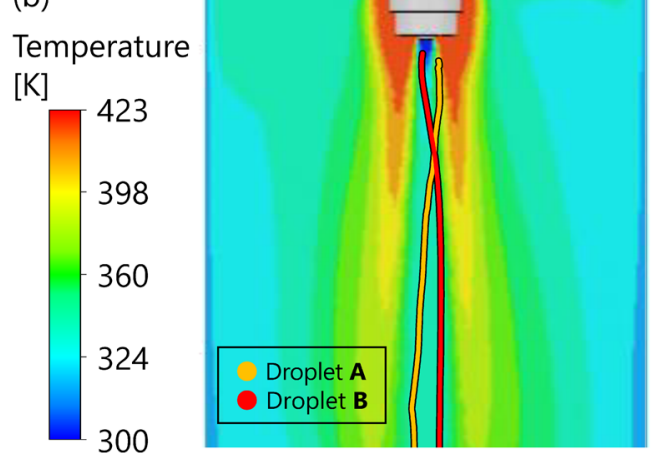

Fig. 4. (a) $D^{2}$-Plots and $\Delta T$ of Two Arbitrary Droplets (Yellow; Droplet A, Red; Droplet B); (b) Droplet Trajectories of Droplet A and B Depicted on Air Temperature Profiles

(Color figure can be accessed in the online version.) 


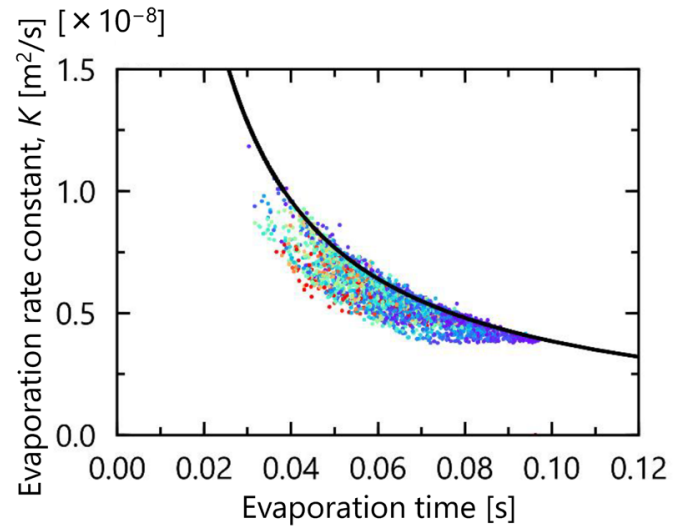

Square of the coefficient of correlation, $\mathrm{R}^{2}$

$\begin{array}{lllllll}1.000 & 0.995 & 0.990 & 0.985 & 0.980 & 0.975 & 0.970\end{array}$

Fig. 5. Relationship between Droplet Evaporation Time and $K$ Color Coded by Square of Coefficient of Correlation, $R^{2}$

(Color figure can be accessed in the online version.)

$$
\left[\times 10^{-10}\right]
$$

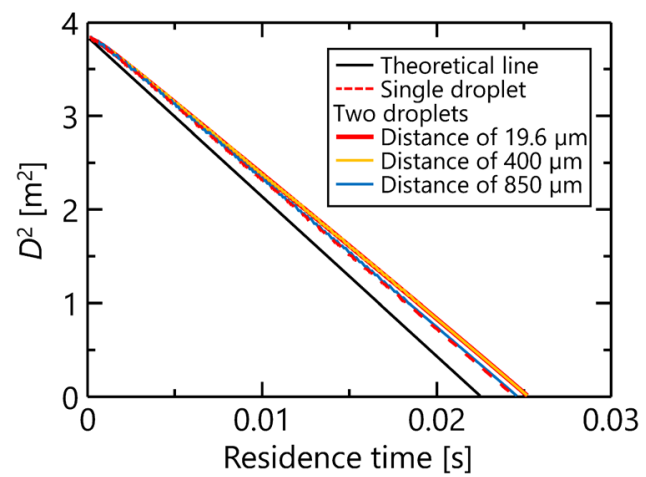

Fig. 6. $D^{2}$-Plots of Droplets Arranged with Different Distances between Droplets in a Simple Cylinder

(Color figure can be accessed in the online version.)

Table 2. Results of Calculated $K$ and Droplet Evaporation Time in a Simple Cylinder under Different Distances between Droplets

\begin{tabular}{lccc}
\hline \hline & $K \times 10^{8}\left[\mathrm{~m}^{2} / \mathrm{s}\right]$ & $R^{2}$ & Drying time $[\mathrm{s}]$ \\
\hline Theoretical line & 1.7030 & 1.000 & 0.0255 \\
Single droplet & 1.5883 & 0.99992 & 0.0244 \\
Two droplets & & & \\
Distance of $19.6 \mu \mathrm{m}$ & 1.5373 & 0.99990 & 0.0252 \\
Distance of $400 \mu \mathrm{m}$ & 1.5372 & 0.99985 & 0.0252 \\
Distance of $850 \mu \mathrm{m}$ & 1.5775 & 0.99991 & 0.0246 \\
\hline
\end{tabular}

line in Fig. 5 indicates the value obtained using Eq. 15 under the assumption that the $D^{2}$-plots show a straight line. Especially focusing on the evaporation time of $0.06-0.07 \mathrm{~s}$, which is near the mode of the droplet evaporation time shown in Fig. 2 (a), the plots with $K$ smaller than the ideal value (solid line) have smaller $R^{2}$ values. In addition, the cumulative probability (Supplementary Fig. S3 (a)) confirmed that half of the droplets had an $R^{2}$ of less than 0.99 (see Supplementary Materials for the detailed results). In the case of smaller $R^{2}$ values, the $D^{2}$ plots are curved because of a large $\Delta T$ change. In summary, the distribution of $K$ in the droplet group was governed by the change in $\Delta T$ caused by the nonuniform temperature field inside the drying tower and the different trajectories of the droplets.

Effect of Adjacent Droplets on the Evaporation Rate The effects of each droplet in the droplet group on each other were analyzed using the simple cylinder geometry. First, the average distance between the droplets in the spray drying tower was calculated. The drying tower was divided into $0.0478 \mathrm{~m}$ in height, $0.005 \mathrm{~m}$ in width, and $0.005 \mathrm{~m}$ in depth, and the average distance between the droplets was calculated from the lattice volume and number of the droplets in each grid based on the following expression:

$$
\text { Average distance }[\mathrm{m}]=\sqrt[3]{\frac{\text { Lattice volume }\left[\mathrm{m}^{3}\right]}{\text { Number of droplets in the grid }[\#]}},
$$

It was found that the distance between the droplets in the spray drying tower was approximately $400 \mu \mathrm{m}$ at the bottom of the nozzle, where the droplets were dense. Outside of the droplet group where the droplet number density was small, the distance between the droplets was approximately $1 \mathrm{~mm}$. Based on these results, the evaporation process of two droplets placed perpendicular to the drying airflow was calculated. The distance between the droplets was set to $19.6,400$, and $850 \mu \mathrm{m}$ to investigate the effect of the distance between the droplets on the evaporation behavior. Figure 6 shows the temporal change in the droplet squared diameter, which is the $D^{2}$-plots, calculated under different distances and numbers of droplets. The dashed black line is the theoretical $D^{2}$-plot of a single droplet calculated using Eq. 16 under the assumption that the temperature difference between the droplet and ambient air is constant $(423 \mathrm{~K})$. The calculated $K$ and the droplet evaporation time are summarized in Table 2. When one droplet was placed in the cylinder (dashed red line), the evaporation rate was slower than the theoretical one, which was attributed to the temperature decrease of the surrounding air owing to droplet evaporation. In the case of two droplets, the evaporation rate decelerated with a distance of $400 \mu \mathrm{m}$ between the droplets, while the distance between $850 \mu \mathrm{m}$ droplets indicated the same value of $K$ in the case of a single droplet. This was because the evaporated water vapor affected the driving force, $\Delta H$ of the adjacent droplets. The distance threshold affecting the evaporation rate of the adjacent droplet can be determined by the diffusion coefficient of water vapor in air. In this study, the diffusion coefficient of vapor in air was set to $2.88 \times 10^{-5} \mathrm{~m}^{2} / \mathrm{s}$. The times for water vapor to diffuse through the 400 and $850 \mu \mathrm{m}$ were 0.0056 and $0.025 \mathrm{~s}$, respectively. As the evaporation time was less than $0.01 \mathrm{~s}$, droplets with a distance of $850 \mu \mathrm{m}$ or more did not affect the evaporation rate of other droplets. In summary, when the distance between the droplets was larger than a certain value, the effect of the adjacent droplets was neglected, implying the similar evaporation behavior as that of a single droplet. Furthermore, the distance threshold can be estimated from the diffusion coefficient of water vapor in air.

To investigate the effect of the number of droplets on $K$, the evaporation process of 4-300 droplets arranged in a grid in the cylinder with a distance of $400 \mu \mathrm{m}$ were calculated. The average evaporation rate constant $K$ was obtained from the $D^{2}$-plot of each droplet. Figure 7 (a) shows the relationship between the number of droplets and $K$. The error bars represent 
(a) $\left[\times 10^{-8}\right]$

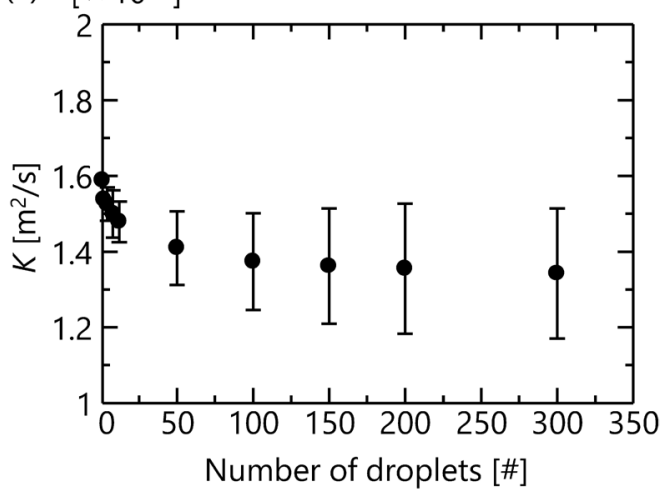

(b)

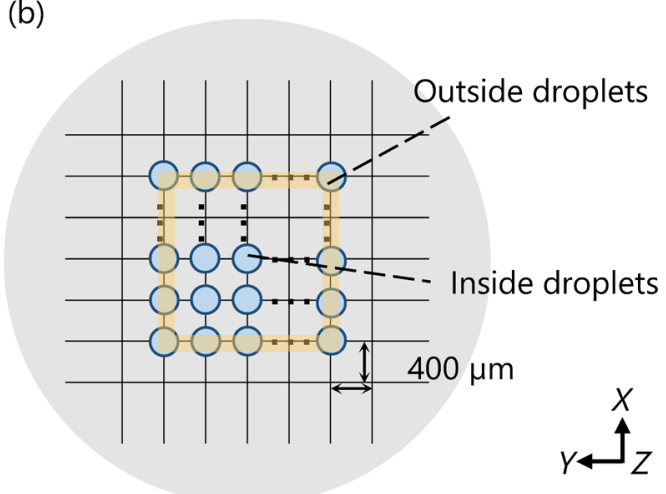

Fig. 7. (a) Relationship between Number of Droplet and $K$ in a Simple Cylinder; (b) Outside and inside Droplets Arranged in a Grid in a Simple Cylinder (Top View)

(Color figure can be accessed in the online version.)

the maximum and minimum values of $K$. The value of $K$ decreased as the number of droplets increased and eventually became constant at 100 or more droplets. This can be explained by the increase in the number of droplets inside the droplet group. When a large number of droplets were placed, the outer droplets (the vertex and edge of the lattice) in contact with hot air evaporated quickly, while the inner droplets (inside the lattice) evaporated slowly. In this calculation setting (the distance between droplets of $400 \mu \mathrm{m}$; the diffusion coefficient of water vapor in air of $2.88 \times 10^{-5} \mathrm{~m}^{2} / \mathrm{s}$ ), although two adjacent droplets affected each other, the effect of farther droplets was negligible. Therefore, when a large number of droplets were arranged in a grid, the evaporation rate constant of the droplet group was determined from the number of outside and inside droplets (Fig. 7 (b)). In other words, as the number of inner droplets increased, the $K$ of the entire droplet group gradually approached the value of $K$ of the inner droplets.

From the results above, it was found that the driving force for evaporation, $\Delta H$, fluctuated owing to the effect of adjacent droplets, which decreased the evaporation rate of the droplets. This was a major influencing factors to the difference in the evaporation rate of each droplet in the droplet group during the spray drying process, in addition to the change in $\Delta T$ mentioned in "Evaluation of Evaporation Rate Constant in Spray Dryer." Obtained simulation results quantitatively demonstrated the effect of adjacent droplets on the evaporation, which would affect the drying behavior of individual droplets in the droplet group.

\section{Conclusion}

In the present study, the evaporation behavior of a droplet group in the spray drying process was analyzed using the CFD-DPM simulations in a mini co-current-spray dryer. The evaporation behavior of each droplet was analyzed based on classical $D^{2}$-law. Our investigation yielded the following conclusions:

1. The temporal change in $D^{2}$ and the temperature/humidity difference $(\Delta T, \Delta H)$ between the droplets and surrounding air, which were the driving forces for the droplet evaporation, were analyzed. It was quantitatively indicated that the evaporation rate constant, $K$ depended on the values of $\Delta T$ and $\Delta H$.

2. The calculation results using a simple cylinder geometry suggested that the prediction of the evaporation rate of the droplet group was insufficient under the assumption of the steady conditions. In addition, it was revealed that the effect of adjacent droplets was one of the major contributors to the difference in the evaporation rate of each droplet in the droplet group.

Our simulation results demonstrated that owing to the complicated flow in the drying tower and the effect of the surrounding numerous droplets, the evaporation behavior deviated significantly from the ideal system, and individual droplets exhibited different evaporation rates. By applying this achievement to the falling drying rate period, a more detailed understanding of the spray drying process will be promoted. These investigations would lead to the determination of precise operating conditions of the spray drying process required for the design and manufacturing of pharmaceutical drugs.

\section{Nomenclature}

$C \quad:$ molar vapor concentration $\quad\left[\mathrm{mol} / \mathrm{m}^{3}\right]$

$C_{\mathrm{D}} \quad$ : drag coefficient

$c_{\mathrm{p}} \quad$ : heat capacity

$D \quad$ : inner diameter of the drying tower

d : droplet diameter

$D_{\mathrm{AB}}:$ diffusion coefficient of vapor in air

E : total energy

$\boldsymbol{F} \quad$ : fluid drag force

$G \quad$ : mass velocity

g : gravity acceleration

$H \quad$ : heat

$h \quad:$ heat transfer coefficient, sensible enthalpy

$h_{\text {col }}:$ film coefficient of heat transfer

$h_{\mathrm{fg}} \quad$ : specific heat of evaporation

$\boldsymbol{J}_{j} \quad$ : diffusion flux of species $j$

$K \quad$ : evaporation rate constant

$k \quad:$ thermal conductivity

$k_{\mathrm{c}} \quad:$ mass transfer efficient

$k_{\text {eff }}:$ effective conductivity

$M \quad$ : molar mass

$m$ : mass

$[\mathrm{J} / \mathrm{kg} \cdot \mathrm{K}]$

$\mathrm{g} \cdot \mathrm{K}]$

[m]

$\left[\mathrm{m}^{2} / \mathrm{s}\right]$

[N]

$\left[\mathrm{kg} / \mathrm{m}^{2} \cdot \mathrm{s}\right]$

$\left[\mathrm{m} / \mathrm{s}^{2}\right]$

$[\mathrm{J} / \mathrm{kg}]$

$\left[\mathrm{W} / \mathrm{m}^{2} \cdot \mathrm{K}\right]$

$\left[\mathrm{W} / \mathrm{m}^{2} \cdot \mathrm{K}\right]$

$[\mathrm{J} / \mathrm{kg}]$

$\left[\mathrm{kg} / \mathrm{m}^{2} \cdot \mathrm{s}\right]$

$\left[\mathrm{m}^{2} / \mathrm{s}\right]$

$[\mathrm{W} / \mathrm{m} \cdot \mathrm{K}]$

$[\mathrm{m} / \mathrm{s}]$

$[\mathrm{W} / \mathrm{m} \cdot \mathrm{K}]$

$[\mathrm{kg} / \mathrm{mol}]$

$[\mathrm{kg}$

$p \quad:$ pressure of fluid $\quad[\mathrm{Pa}]$

$Q \quad$ : heat transfer between the continuous phase and the discrete phase

$R \quad$ : universal gas constant

$[\mathrm{J} / \mathrm{K} \cdot \mathrm{mol}]$

$T$ : temperature

: time

: velocity

$\mathrm{Nu}$ : Nusselt number

Re : Reynolds number 


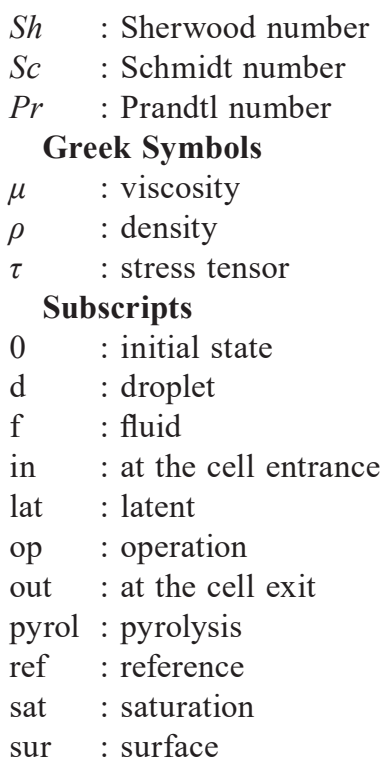

Acknowledgments This work is financially supported in part by a Grant-in-Aid for Early-Career Scientists (No. 19K15344) of Japan Society for the Promotion of Science (JSPS). We would like to acknowledge to the ANSYS Academic Partner Program for providing ANSYS software.

Conflict of Interest The authors declare no conflict of interest.

Supplementary Materials The online version of this article contains supplementary materials.

\section{References}

1) Vehring R., Pharm. Res., 25, 999-1022 (2008).

2) Sollohub K., Cal K., J. Pharm. Sci., 99, 587-597 (2010).

3) Paudel A., Worku Z. A., Meeus J., Guns S., Van den Mooter G., Int. J. Pharm., 453, 253-284 (2013).

4) Singh A., Van den Mooter G., Adv. Drug Deliv. Rev., 100, 27-50 (2016).

5) Tanida S., Yoshimoto A., Yoshida M., Uchiyama H., Kadota K., Tozuka Y., Chem. Pharm. Bull., 67, 921-928 (2019).

6) Li Z., Lin X., Shen L., Hong Y., Feng Y., Int. J. Pharm., 519, 272 286 (2017)

7) Arpagaus C., Collenberg A., Rutti D., Assadpour E., Jafari S. M., Int. J. Pharm., 546, 194-214 (2018).

8) Nakashima A., Izumi T., Ohya K., Kondo K., Niwa T., Chem. Pharm. Bull., 65, 157-165 (2017).

9) Joshi S., Petereit H. U., Int. J. Pharm., 457, 395-406 (2013).

10) Ozeki T., Tagami T., Asian J. Pharm. Sci., 9, 236-243 (2014).

11) Fu N., Woo M. W., Chen X. D., Dry. Technol., 30, 1771-1785 (2012).
12) Farid M., Chem. Eng. Sci., 58, 2985-2993 (2003).

-] 13) Zhifu Z., Guoxiang W., Bin C., Liejin G., Yueshe W., Powder Technol., 240, 95-102 (2013).

14) Gopireddy S. R., Gutheil E., Int. J. Heat Mass Transfer, 66, 404411 (2013).

15) Grosshans H., Griesing M., Mönckedieck M., Hellwig T., Walther B., Gopireddy S. R., Sedelmayer R., Pauer W., Moritz H.-U., Urbanetz N. A., Gutheil E., Int. J. Heat Mass Transfer, 96, 97-109 (2016).

16) Grosshans H., Griesing M., Hellwig T., Pauer W., Moritz H.-U., Gutheil E., Powder Technol., 297, 259-265 (2016).

17) Chew J. H., Woo M. W., Chen X. D., Selomulya C., Dry. Technol., 33, 1101-1113 (2015).

18) Maurice U., Mezhericher M., Levy A., Borde I., Dry. Technol., 31, 1790-1807 (2013).

19) Fletcher D. F., Guo B., Harvie D. J. E., Langrish T. A. G., Nijdam J. J., Williams J., Appl. Math. Model., 30, 1281-1292 (2006).

20) Mezhericher M., Levy A., Borde I., Dry. Technol., 33, 2-23 (2014).

21) Langrish T. A. G., Williams J., Fletcher D. F., Chem. Eng. Res. Des., 82, 821-833 (2004).

22) Wawrzyniak P., Jaskulski M., Zbiciński I., Podyma M., Adv. Powder Technol., 28, 167-176 (2017).

23) Cotabarren I. M., Bertín D., Razuc M., Ramírez-Rigo M. V., Piña J., Chem. Eng. Res. Des., 132, 1091-1104 (2018).

24) Afshar S., Metzger L., Patel H., Selomulya C., Woo M. W., Dry. Technol., 37, 824-838 (2018).

25) Sebastia-Saez D., Hernandez L., Arellano-Garcia H., Julia J. E., Chem. Eng. Sci., 195, 83-94 (2019).

26) Mezhericher M., Levy A., Borde I., Chem. Eng. Process., 49, $1205-$ 1213 (2010).

27) Jaskulski M., Wawrzyniak P., Zbiciński I., Adv. Powder Technol., 29, 1724-1733 (2018).

28) Jubaer H., Afshar S., Xiao J., Chen X. D., Selomulya C., Woo M. W., Dry. Technol., 36, 1785-1801 (2017).

29) Ali M., Mahmud T., Heggs P. J., Ghadiri M., Bayly A., Ahmadian H., Juan L. M. d., Procedia Manuf., 102, 1284-1294 (2015).

30) Ali M., Mahmud T., Heggs P., Ghadiri M., Bayly A., Crosby M., Ahmadian H., Martindejuan L., Alam Z., Powder Technol., 305, 809-815 (2017).

31) Gianfrancesco A., Turchiuli C., Flick D., Dumoulin E., Food Bioproc. Tech., 3, 946-955 (2010).

32) Schmitz-Schug I., Kulozik U., Foerst P., Food Bioproc. Tech., 7, 877-886 (2013)

33) Schmitz-Schug I., Kulozik U., Foerst P., Chem. Eng. Sci., 141, 315-329 (2016).

34) Okada S., Ohsaki S., Nakamura H., Watano S., Chem. Eng. Sci., 227, 115938 (2020)

35) Patankar S. V., "Numerical Heat Transfer and Fluid Flow," Hemisphere Publishing Corporation, U.S.A., 1980.

36) Shih T.-H., Liou W. W., Shabbir A., Yang Z., Zhu J., Comput. Fluids, 24, 227-238 (1995).

37) Ranz W. R., Chem. Eng. Prog., 48, 141-173 (1952).

38) Colburn A. P., de E. I. P., Ind. Eng. Chem., 25, 873-877 (1933).

39) Law C. K., Pror. Energy Combust. Sci., 8, 171-201 (1982). 